\title{
A MODIFIED PROCEDURE TO EVALUATE ACTIVE EARTH PRESSURE AT HIGH SEISMIC LOADS
}

\author{
Junichi Koseki ${ }^{\text {i), Fumio TAtSuOKa }}{ }^{\text {ii), }}$, Yulman MunaFiii), \\ MASARU TATEYAMA ${ }^{\text {iv) }}$ and KenICHI KOJIMA ${ }^{\text {v) }}$
}

\begin{abstract}
A modified and pseudo-static limit-equilibrium approach to evaluate active earth pressure at high seismic load levels is proposed. Although it is similar to the Mononobe-Okabe method, the proposed method considers the effects of strain localization in the backfill soil and associated post-peak reduction in the shear resistance from peak to residual values along a previously formed failure plane. The proposed method can reflect differences in the peak shear resistance of the backfill soil with different degrees of compaction; yields a realistic active earth pressure coefficient which is smaller than that predicted by the Mononobe-Okabe method using a residual shear resistance; can be adapted to analyses with a large horizontal seismic coefficient where the Mononobe-Okabe method using the residual shear resistance is not applicable; and renders a reduced and more realistic size of active failure zone in the backfill soil at high seismic load levels compared to that predicted by the Mononobe-Okabe method.
\end{abstract}

Key words: active earth pressure, earthquake, (failure plane), (limit equilibrium method), residual strength, retaining wall, sand, (strain localization) (IGC: E5/E8)

\section{INTRODUCTION}

The well-known Mononobe-Okabe method, based on a pseudo-static and limit-equilibrium approach, was proposed to calculate the seismic earth pressure (Okabe, 1924; Mononobe and Matsuo, 1929). Since then, a variety of shaking model tests have been conducted to study on the seismic earth pressure. For example, Ohara et al. (1970) showed that the total active earth pressure measured in their sinusoidally shaken model tests was consistent with the value calculated by the Mononobe-Okabe method when the shear resistance angle of the backfill soil was assumed to decrease as the shaking acceleration increased. They also showed that the vertical distribution of the measured active earth pressure was not hydrostatic but dependent on the displacement mode of the model wall. Other similar investigations include those by Ichihara and Matsuzawa (1973) and Ishibashi and Fang (1987). It was suggested by these previous investigations that, in general, the Mononobe-Okabe method can reasonably predict the total active earth pressure during earthquake, although its point of application is located higher than that derived from the assumption of hydrostatic distribution, which may lead to an underestimation of overturning moment of the wall due to the earth pressure. It is to be noted that seismic loads examined in the experimental studies were limited to relatively low levels; the amplitude of input acceleration was smaller than $500 \mathrm{~cm} / \mathrm{sec}^{2}$.

For retaining walls with relatively less importance, aseismic design is usually omitted by assuming that a wall that is designed against static loads has a safety margin and the margin would cover the additional resistance required against seismic loads (e.g., JRA, 1987). In many of the design specifications or guidelines in Japan for relatively important retaining walls, the Mononobe-Okabe method has been adopted together with the assumption of hydrostatic distribution to evaluate the seismic active earth pressure. Alternatively, the trial wedge method, which is in principle equivalent to the Mononobe-Okabe method when the surface of the backfill soil is flat, has been employed for backfill soil having an irregular crosssection. In these aseismic design procedures, relatively small values are assigned for the shear resistance angle of

i) Associate Professor, Institute of Industrial Science, University of Tokyo, Roppongi 7-22-1, Minato-ku, Tokyo 106-8558.

ii) Professor, Department of Civil Engineering, University of Tokyo, Hongo 7-3-1, Bunkyo-ku, Tokyo 113-8656.

iii) Graduate Student, Institute of Industrial Science, University of Tokyo, Roppongi 7-22-1, Minato-ku, Tokyo 106-8558.

iv) Chief Engineer, Railway Technical Research Institute, Hikari-machi 2-8-38, Kokubunji city, Tokyo 185-8540.

v) Engineer, Railway Technical Research Institute, ditto.

Manuscript was received for review on August 25, 1997.

Written discussions on this paper should be submitted before April 1, 1999 to the Japanese Geotechnical Society, Sugayama Bldg., 4F, Kanda Awaji-cho, 2-23, Chiyoda-ku Tokyo 101-0063, Japan. Upon request the closing date may be extended one month. 
Table 1. Design shear resistance angles of backfill soil assigned to evaluate earth ressure (after RTRI, 1997)

\begin{tabular}{ll|c}
\hline & Type of backfill soil & $\begin{array}{c}\text { Shear resistance } \\
\text { angle in degrees }\end{array}$ \\
\hline 1) & $\begin{array}{l}\text { Well graded sand, gravel and muck } \\
\text { from hard rock }\end{array}$ & 40 \\
\hline 2) & Sand and gravel other than 1) and 3) & 35 \\
\hline 3) Poorly graded sand & 30 \\
\hline 4) $\quad$ Cohesive soil* & 30 \\
\hline$* \quad \begin{array}{l}\text { For retaining walls not higher than 6m and embankments not } \\
\text { higher than 10 m; cohesion is empirically replaced by shear } \\
\text { resistance angle. }\end{array}$
\end{tabular}

the backfill soil, as typically shown in Table 1 . These shear resistance angles are apparently lower than the peak angles of the backfill that is compacted to a dense state as specified by the design specifications; rather these values are similar to the residual angles. The use of such low friction angles may lead to a conservative aseismic design or may be balanced with the use of relatively low design seismic loads. On the other hand, the assumption of the hydrostatic distribution may be less conservative by itself, as mentioned before.

The 1995 Hyogoken-Nanbu earthquake caused severe damage to a number of conventional type retaining walls, particularly gravity-type retaining walls, for railway and road embankments (Tatsuoka et al., 1996a and 1996b). The peak ground acceleration (PGA) at the sites of these severely damaged retaining walls were estimated to be very high, up to $800 \mathrm{~cm} / \mathrm{sec}^{2}$ (Koseki et al., 1996). In contrast, even when subjected to such a high seismic load, some modern reinforced-concrete $(\mathrm{RC})$ retaining walls and geosynthetic-reinforced soil retaining walls located at Tanata and other locations performed satisfactorily (Tatsuoka et al., 1996a). To understand the behavior of such damaged and undamaged retaining walls which experienced very high seismic loads, stability analysis of these retaining walls using a high seismic coefficient that exceeds, for example, 0.5 is required (Koseki et al., 1996).

After the earthquake, a two stage aseismic design procedure based on two different levels for the combination of seismic load and expected structural performance has been proposed to be applied to several types of civil engineering structures (JSCE, 1996), and retaining walls are not an exception. For example, the standard horizontal design seismic coefficient employed to evaluate the earth pressure during earthquake is assigned 0.2 (level 1) and 0.4 (level 2) for the aseismic design of retaining walls for railways on serviceability limit and ultimate limit conditions, respectively (RTRI, 1997). It should also be noted that use of relatively low soil strength as listed in Table 1 is suggested in the above mentioned design procedure. When using design shear resistance angles for the backfill soil such as 30 to 40 degrees, the MononobeOkabe method provides unrealistically high active earth pressure when such high seismic coefficients, which are equivalent to or larger than the level 2 seismic load, are applied, as will be described later. It is, therefore, necessary to develop a new procedure, which can evaluate the active earth pressure for relatively high seismic loads.

In this paper, a modified procedure to evaluate active earth pressure at high seismic loads is proposed based on the pseudo-static and limit-equilibrium approach. Differently from the Mononobe-Okabe method, it considers the effects of strain localization in the backfill soil and associated post-peak reduction in the shear resistance along a previously formed failure plane. Possible advantages of the proposed procedure over the Mononobe-Okabe method are also discussed.

\section{MONONOBE-OKABE METHOD}

The Mononobe-Okabe method (denoted herein as "M-O method") considers the effects of on inertia force acting uniformly in the backfill soil having a Coulomb type soil wedge, with its horizontal and vertical components $k_{h} \cdot W$ and $k_{v} \cdot W$, respectively (see Fig. 1 , where $W$ is the self weight of the soil wedge, $k_{h}$ and $k_{v}$ are the horizontal and vertical seismic coefficients). The total active earth pressure $P_{a}$ can be evaluated as;

$$
P_{a}=1 / 2 \cdot \gamma H^{2} \cdot\left(1-k_{v}\right) \cdot K_{a}
$$

where $\gamma$ is the unit weight of the backfill soil, $H$ is the total height of the retaining wall, and $K_{a}$ is the active earth pressure coefficient calculated as;

$$
K_{a}=\frac{\cos ^{2}(\phi-\psi-\theta)}{\cos \theta \cdot \cos ^{2} \psi \cdot \cos (\delta-\psi-\theta)\left[1+\sqrt{\frac{\sin (\phi+\delta) \cdot \sin (\phi-\beta-\theta)}{\cos (\delta+\psi+\theta) \cdot \cos (\psi-\beta)}}\right]^{2}}
$$

Here $\phi$ is the soil shear resistance angle which is uniform and isotropic in the backfill, $\delta$ is the frictional angle at the interface between the back face of the retaining wall and the backfill soil, $\psi$ is the inclination of the back face of the retaining wall measured from the vertical direction, $\beta$ is the angle of the surface slope of the backfill soil measured from the horizontal direction, and $\theta$ denotes the direction of the total of the inertia force and the self weight of the soil wedge measured from the vertical, which is given by;

$$
\theta=\tan ^{-1}\left(k_{h} /\left(1-k_{v}\right)\right)
$$

The angle $\alpha$, measured from the horizontal direction, defines the direction of the failure plane, which is the bottom plane of the critical soil wedge mobilized at active failure condition. The angle $\alpha$ can be calculated from; 


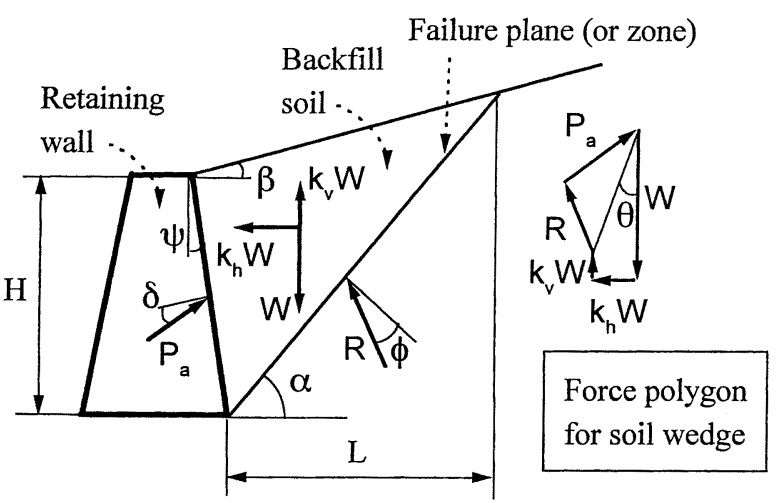

Fig. 1. Schematic diagram of forces acting on soil wedge assumed by the Mononobe-Okabe method

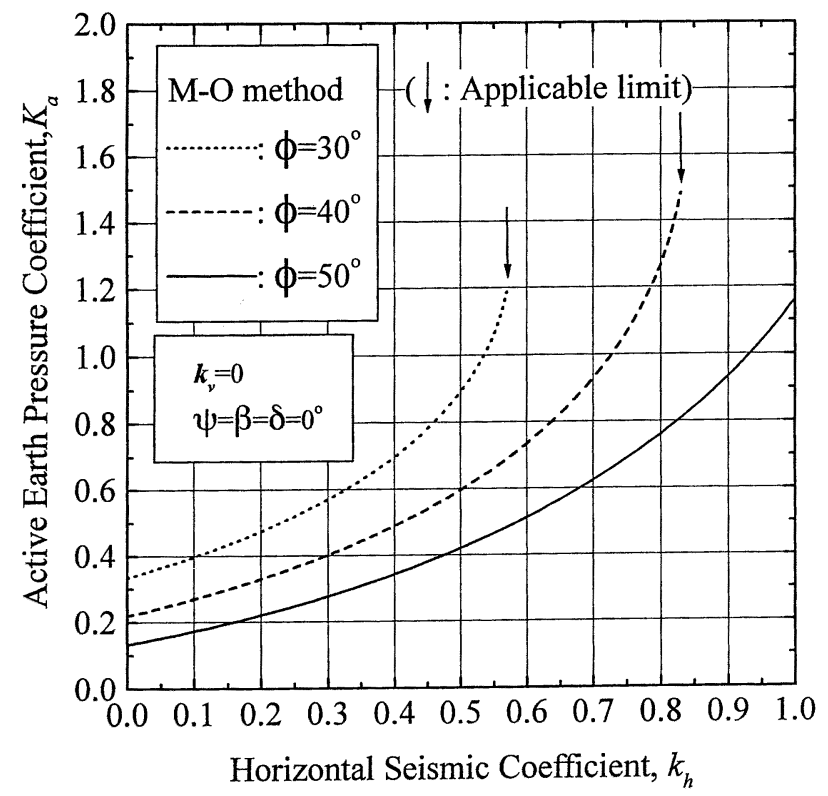

(a)

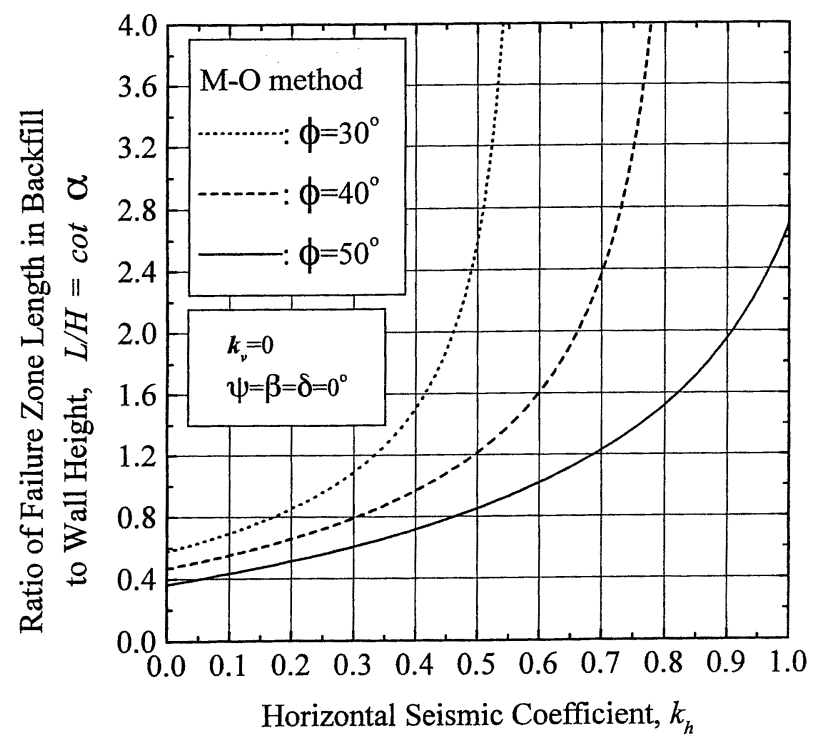

(b)

Fig. 2. (a) Active earth pressure coefficient, (b) ratio of failure zone length in backfill soil to wall height by the Mononobe-Okabe method for $\phi=30^{\circ}, 40^{\circ}, 50^{\circ}$ and $\delta=0^{\circ}$

$$
\begin{aligned}
\cot (\alpha-\beta)= & -\tan (\phi+\delta+\psi-\beta)+\sec (\phi+\delta+\psi-\beta) \\
& \cdot \sqrt{\frac{\cos (\phi+\delta+\theta) \cdot \sin (\phi+\delta)}{\cos (\psi-\beta) \cdot \sin (\phi-\beta-\theta)}}
\end{aligned}
$$

Then the ratio of the failure zone length $L$ in the backfill soil, which is defined in Fig. 1, to the wall height $H$ is given by;

$$
L / H=(1+\tan \psi \cdot \tan \beta) /(\tan \alpha-\tan \beta)
$$

As an example, the active earth pressure coefficient $K_{a}$ and the ratio $L / H$ are plotted versus the horizontal seismic coefficient $k_{h}$, respectively, in Figs. 2(a) and (b). For this case, $k_{v}, \psi, \beta$ and $\delta$ are all zero and the value of $\phi$ is set equal to 30,40 and 50 degrees. With a constant $\phi$, the value of $K_{a}$ gradually increases with an increase in $k_{h}$. There are applicable upper limits of $k_{h}$ in the M-O method as indicated by arrows in Fig. 2(a), beyond which $K_{a}$ cannot be evaluated where the term of " $\phi-\beta-\theta$ " in the square-root term in Eq. (2) becomes negative. This corresponds to a condition in which the pseudo-static equilibrium of forces acting on the assumed soil wedge as shown in Fig. 1 cannot be maintained, resulting in unstable behavior of the backfill soil, such as flow slide at its surface.

As seen from Fig. 2(b), the ratio $L / H$ also increases as $k_{h}$ increases. The rate of increase in $L / H$ is accelerated, and the value of $\mathrm{L} / \mathrm{H}$ becomes an unrealistically large value when $k_{h}$ approaches and reaches the applicable limit explained above.

\section{EFFECTS OF STRAIN LOCALIZATION}

In the M-O method, the shear resistance of the backfill soil is assumed to be uniform, isotropic and constant. It has been shown, however, that the behavior of a soil mass is affected by such factors as strength anisotropy, progressive failure and strain localization. Among these, effects of strain localization into a shear band (or a failure plane) and associated strain-softening in the shear band will be considered in the proposed procedure. Effects of essential difference between the actual dynamic behavior of the wall-soil system and its modeling based on the pseudo-static and limit-equilibrium approach is beyond the scope of the present paper.

Yoshida et al. (1994) and Yoshida and Tatsuoka (1997) conducted a series of plane strain compression tests on dense sands and gravels to obtain the deformation properties of shear band. Figure 3 provides typical results showing the relationships between the shear stress level defined as $R=\left\{\left(\sigma_{1} / \sigma_{3}\right)-\left(\sigma_{1} / \sigma_{3}\right)_{\text {res }}\right\} /\left\{\left(\sigma_{1} / \sigma_{3}\right)_{\text {peak }}-\left(\sigma_{1} /\right.\right.$ $\left.\left.\sigma_{3}\right)_{\text {res }}\right\}$ and the normalized shear displacement increment $\left(u_{s}-\left(u_{s}\right)_{\text {peak }}\right) / D_{50}$ which occurred across a shear band after the peak state. Here the subscripts "peak" and "res" denote the peak and the residual states, respectively, and $u_{s}$ is the shear displacement across the shear band. These results were obtained from plane strain compression tests performed at $\sigma_{3}=78 \mathrm{kPa}$, in which local deformation of each specimen on the $\sigma_{2}$ plane was carefully observed to obtain the value of $u_{s}$. It may be seen that a relative dis- 


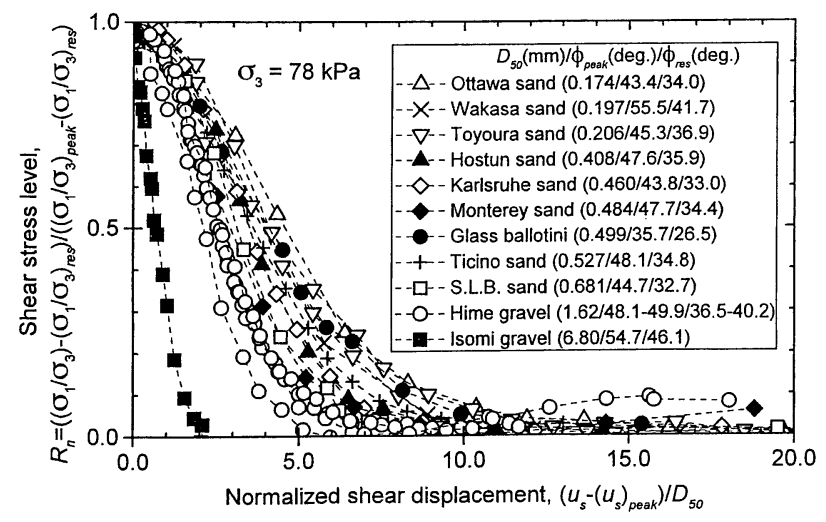

Fig. 3. Relationship between shear stress level $\mathbf{R}=\left\{\left(\sigma_{1} / \sigma_{3}\right)-\left(\sigma_{1} /\right.\right.$ $\left.\left.\sigma_{3}\right)_{\text {res }}\right\} /\left\{\left(\sigma_{1} / \sigma_{3}\right)_{\text {peak }}-\left(\sigma_{1} / \sigma_{3}\right)_{\text {res }}\right\}$ and normalized shear displacement increment $\left(u_{s}-\left(u_{s}\right)_{p e a k}\right) / D_{50} ; \sigma_{1}$ and $\sigma_{3}$ are the boundary average major and minor principal stresses; $\sin \phi_{\text {peak }}=$ $\left\{\left(\sigma_{1} / \sigma_{3}\right)_{\text {peak }}-1\right\} /\left\{\left(\sigma_{1} / \sigma_{3}\right)_{\text {peak }}+1\right\}$ and $\sin \phi_{\text {res }}=\left\{\left(\sigma_{1} / \sigma_{3}\right)_{\text {res }}-1\right\} /$ $\left\{\left(\sigma_{1} / \sigma_{3}\right)_{\text {res }}+1\right\}$ (after Yoshida and Tatsuoka, 1997)

'placement in the direction parallel to the shear band which is enough to reduce the mobilized shear resistance angle from the peak value to the residual value is rather proportional to the particle size and about 5 to 10 times its mean diameter $D_{50}$ (except for Isomi gravel). Based on results from dynamic centrifuge tests on retaining wall models, Bolton and Steedman (1985) also showed that the shear resistance angle mobilized along a failure plane, which was formed in the backfill sand by shaking, dropped from 50 degrees to 33 degrees by a relative displacement of the order of 10 times the mean particle diameter. These results indicate that in full-scale field cases, the drop of soil shear strength from the peak to residual values is very fast.

The amount of outward wall displacement to trigger the active failure of the backfill associated with the mobilization of the peak friction angle in the shear band (or failure plane) is known to be very small; for a wall rotating about its base, the outward displacement at the wall top is about $0.1 \%$ of the wall height from the at rest condition (Terzaghi, 1920). For actual retaining walls, considering their finite bending stiffness and their relatively low resistance against external instability (sliding, overturning and loss of bearing capacity) compared to that against internal instability (physical damage to the wall body), it is likely that only slight deformation or displacement of the wall is enough to trigger active failure in the backfill soil. Therefore, the active failure in the backfill may occur at a seismic level which is far below the level where the ultimate external failure of the wall takes place. This would also be the case with very stiff and statically very stable walls, although the difference between the seismic load level of the active failure in the backfill and the level of the ultimate external wall failure would be smaller. Note that the active failure in the backfill and the ultimate failure of a wall by, for example, complete overturning or unstable large outward sliding at the wall base, are different processes; in most cases, the latter type of failure occurs after the former type of failure has oc-

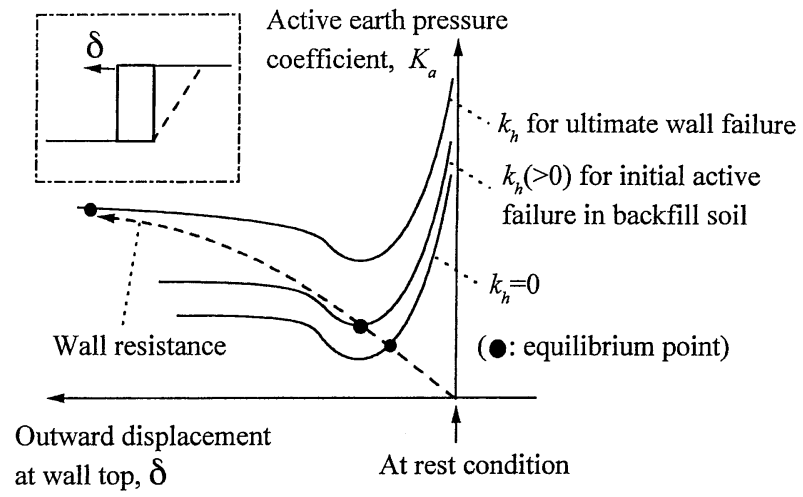

Fig. 4. Schematic relationship between displacement at wall top and active earth pressure coefficient

curred, as schematically shown in Fig. 4. The solid lines in this figure indicate the relationships between the outward displacement of the wall top $\delta$ and the active earth pressure at different seismic load levels, and the dashed line indicates the relationship between $\delta$ and the wall resistance such as the friction at the wall base against the earth pressure. Intersection of these lines at a certain seismic load denotes an equilibrium point at that condition, which moves from right to left in the figure when the seismic load increases, finally reaching the ultimate external wall failure condition. It should be noted that the postpeak reduction of soil shear resistance in the shear band or along the failure plane, which has been formed by the previous active failure (denoted as "initial active failure") prior to the ultimate external wall failure, may affect the consecutive mobilization of earth pressure at higher seismic loads, as illustrated below. The abovementioned process is, in a broad sense, in accordance with the observation by Ohara et al. (1970) described in the INTRODUCTION.

As an example, the active earth pressure coefficient $K_{a}$ was calculated by changing the failure plane angle $\alpha$ based on the equilibrium of forces acting on the soil wedge as shown in Fig. 1. The results are plotted versus $\alpha$ in Figs. 5(a) and (b), where $k_{v}, \psi, \beta$ and $\delta$ are all set zero for simplicity and $\phi$ is assigned to be either 30 or 50 degrees as peak $\left(\phi_{\text {peak }}\right)$ and residual $\left(\phi_{\text {res }}\right)$ values for typical dense sands. For each value of $\phi, k_{h}$ is set at 0 and 0.4 in Fig. 5(a) and 0.62 and 0.8 in Fig. 5(b). The maximum values of $K_{a}$ as indicated by solid horizontal arrows for cases of $\phi=50$ degrees with $k_{h}=0$ to 0.8 are, in principle, equal to those obtained by the M-O method with the same $\phi$, although those values cannot be evaluated for $\phi=30$ degrees with $k_{h}=0.62$ and 0.8 , because these cases are out of the applicable limit of the M-O method, as mentioned previously.

Here, an assumption that the initial active failure occurs at $k_{h}=0$ is employed. Then a failure plane (or a shear band) should be formed at an angle of $\alpha=70$ degrees, which in this case is equal to " 45 degrees $+\left(\phi_{\text {peak }}\right) / 2$ " as derived from the Coulomb's active earth pressure theory with zero values of $k_{h}, k_{v}, \psi, \beta$ and $\delta$. Along this failure plane, the shear resistance angle 


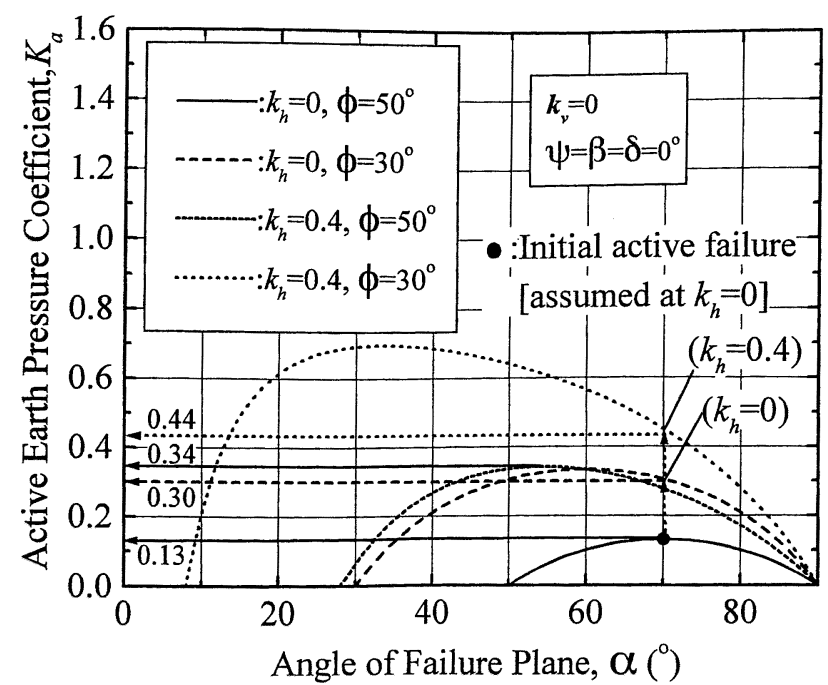

(a)

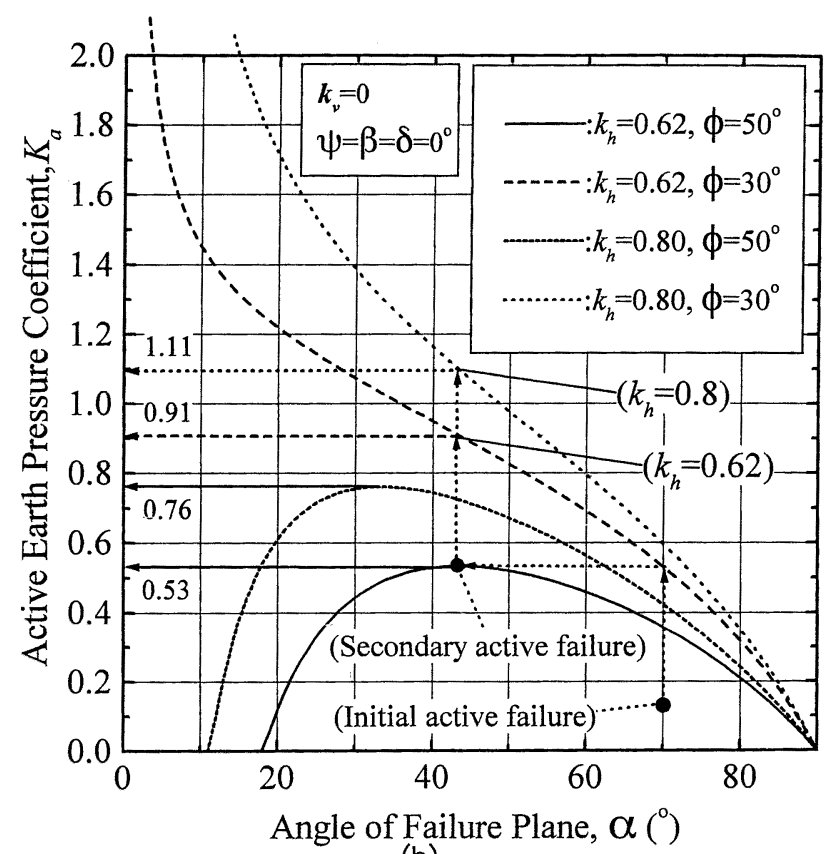

(b)

Fig. 5. Active earth pressure coefficient calculated from equilibrium of forces acting on soil wedge for $\phi=30^{\circ}, 50^{\circ}$ and $\delta=0^{\circ}$ : (a) $k_{h}=0,0.4$, (b) $k_{h}=0.62,0.8$

decreases to $\phi_{\text {res }}=30$ degrees by a slight movement of the wall, while along other potential failure planes, the maximum possible shear resistance angle is still kept at $\phi_{\text {peak }}=50$ degrees. This change results in an increase in the earth pressure at a constant $k_{h}$, after the initial active failure as indicated by the lower vertical dotted arrow shown in Fig. 5(a); i.e., the earth pressure coefficient increases from 0.13 to 0.3 .

When a seismic load equivalent to $k_{h}=0.4$ is applied, the mobilized earth pressure coefficient should be the larger one of "the value of $K_{a}$ obtained for $\phi=\phi_{\text {res }}$ with $k_{h}=0.4$ and $\alpha=70$ degrees" and "the maximum value of $K_{a}$ obtained for $\phi=\phi_{\text {peak }}$ with $k_{h}=0.4$. ." For the latter case, $\alpha$ is equal to the value of $\alpha_{c r}$ which gives the maximum value of $K_{a}$, and the $\alpha_{c r}$ value becomes smaller than
Initial failure plane (assumed at $k_{h}=0$ )

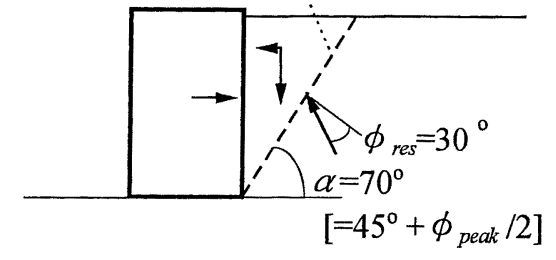

Secondary failure plane (formed at $k_{h}=0.62$ )

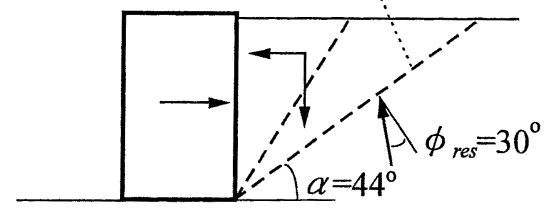

$\left(k_{v}=0, \phi=\beta=\delta=0^{\circ}\right)$

Fig. 6. Initial and secondary active failures considered in the proposed method for $\phi_{\text {peak }}=50^{\circ}, \phi_{\text {res }}=30^{\circ}$ and $\delta=0^{\circ}$

70 degrees. Since the former and the latter values are 0.44 and 0.34 as seen from Fig. 5(a), the earth pressure coefficient mobilized at $k_{h}=0.4$ becomes 0.44 , which is controlled by the failure plane previously formed at the initial active failure. This failure mode will be predominant until $k_{h}$ reaches 0.62 , at which both "the value of $K_{a}$ for $\phi=\phi_{\text {res }}$ with $k_{h}=0.62$ and $\alpha=70$ degrees" and "the maximum value of $K_{a}$ for $\phi=\phi_{\text {peak }}$ with $k_{h}=0.62$ and $\alpha=\alpha_{c r}$ " are equal to 0.53 , as indicated in Fig. 5(b). In this condition of $k_{h}=0.62$, secondary active failure will be triggered by forming another failure plane with an angle of $\alpha=44$ degrees. Then the earth pressure coefficient will increase to 0.91 because of the reduction of the shear resistance angle along this secondary failure plane from $\phi_{\text {peak }}$ to $\phi_{\text {res }}$. This secondary failure plane will control the consecutive behavior in the same manner as above; for example, as shown in Fig. 5(b), the earth pressure coefficient at $k_{h}=0.8$ will become 1.11 when this secondary failure plane is mobilized for $\phi=\phi_{\text {res }}$, which is larger than 0.76 as the maximum value for $\phi=\phi_{\text {peak }}$ with $\alpha=\alpha_{c r}$, which is not equal to 44 nor 70 degrees.

In summary, when the effects of strain localization are considered in the pseudo-static and limit-equilibrium based approach, the failure plane formed by the initial active failure in the backfill soil will control the consecutive mobilization of earth pressure at higher seismic loads until the secondary active failure occurs along another failure plane, which is deeper than the initial one, as schematically illustrated in Fig. 6.

\section{PROPOSED PROCEDURE}

For the proposed procedure, first, the values of $\phi_{\text {peak }}$ and $\phi_{\text {res }}$ of the backfill soil should be evaluated by a proper method, either empirically or experimentally, reflecting the degree of compaction of the backfill. Second, the condition of the initial active failure in the backfill should be evaluated by using the M-O method for 
$\phi=\phi_{\text {peak }}$ to obtain the angle $\alpha$ of the initial failure plane. The relative stiffness of walls and their resistance against external instability should be taken into account when evaluating the initial active failure. Third, the active earth pressure coefficient $K_{a}$ mobilized by the initial failure plane is calculated as;

$$
K_{a}=\frac{\cos (\alpha-\phi) \cdot(1+\tan \psi \cdot \tan \alpha) \cdot(1+\tan \psi \cdot \tan \beta) \cdot(\tan (\alpha-\phi)+\tan \theta)}{\cos (\alpha-\phi-\psi-\delta) \cdot(\tan \alpha-\tan \beta)}
$$

where a reduced shear resistance angle $\phi$ equal to $\phi_{\text {res }}$ is used, and the failure plane angle $\alpha$ is fixed to the critical value $\alpha_{c r}$ for the initial active failure. This coefficient $K_{a}$ is compared with the one evaluated by the M-O method with $\phi=\phi_{\text {peak }}$. If the former value is smaller than the latter, the secondary active failure is judged to have already occurred, for this the critical angle $\alpha_{c r}$ for the secondary

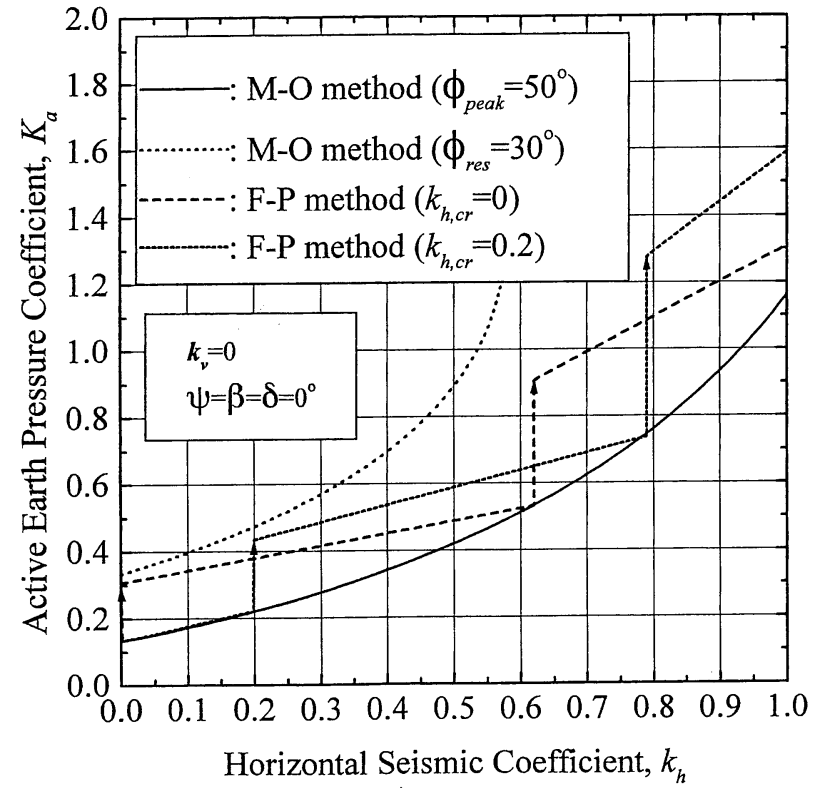

(a)

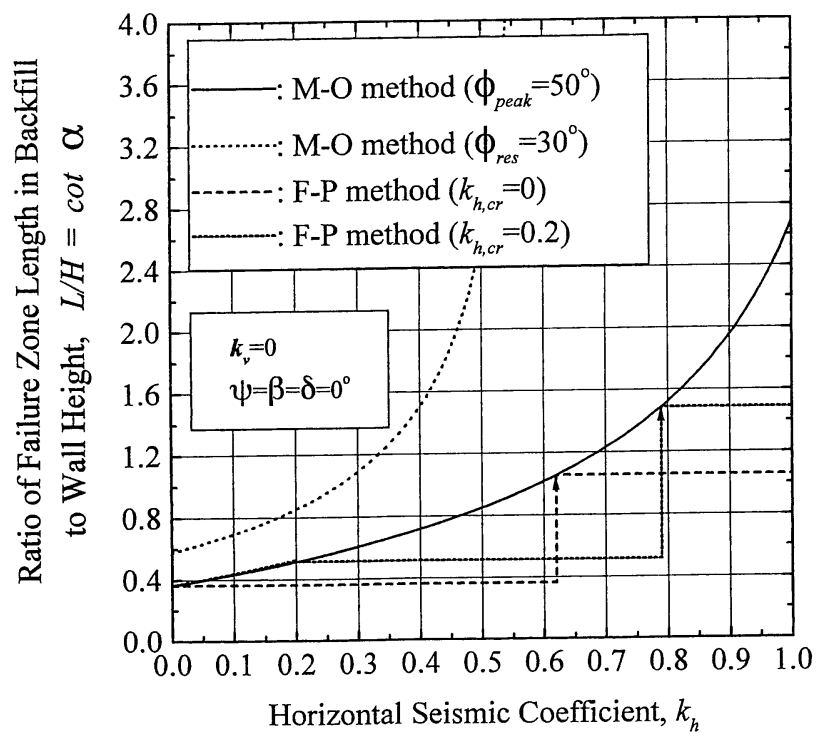

(b)

Fig. 7. (a) Active earth pressure coefficient, (b) ratio of failure zone length in backfill soil to wall height by the proposed method for $\phi_{\text {peak }}=50^{\circ}, \phi_{\text {res }}=30^{\circ}$ and $\delta=0^{\circ}$ failure plane should be re-evaluated in order to calculate the coefficient $K_{a}$ mobilized by this newer failure plane. Otherwise, the coefficient $K_{a}$ calculated for the initial failure plane is considered to be still mobilized.

Values of $K_{a}$ and $L / H=\cot \alpha$ evaluated by the proposed procedure based on the fixed failure plane angle (denoted as "F-P method") are plotted versus $k_{h}$ in

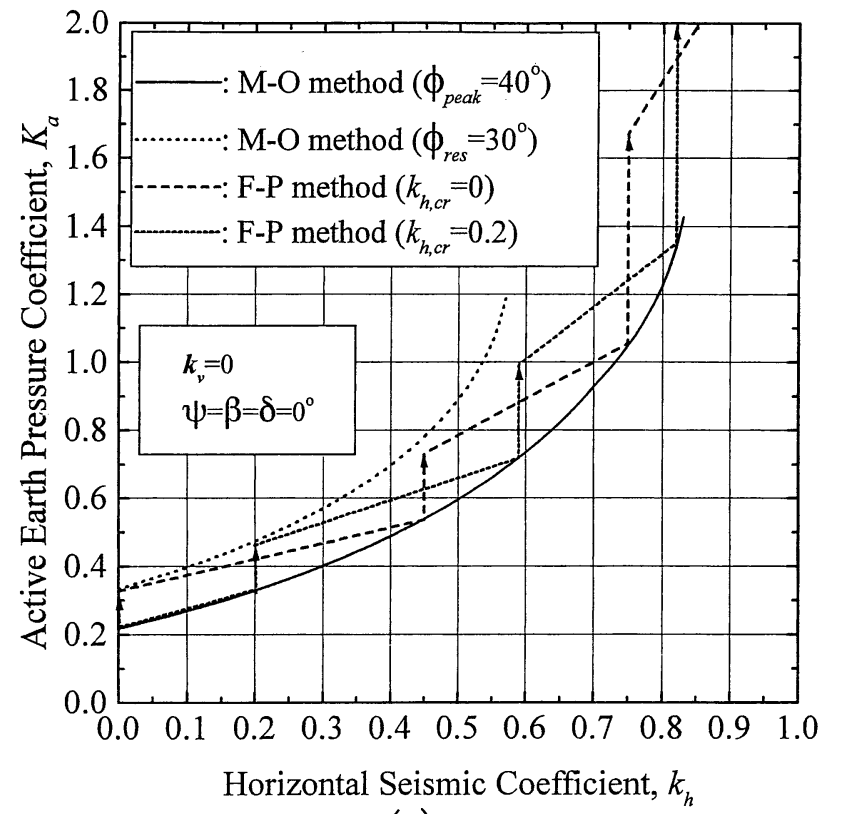

(a)

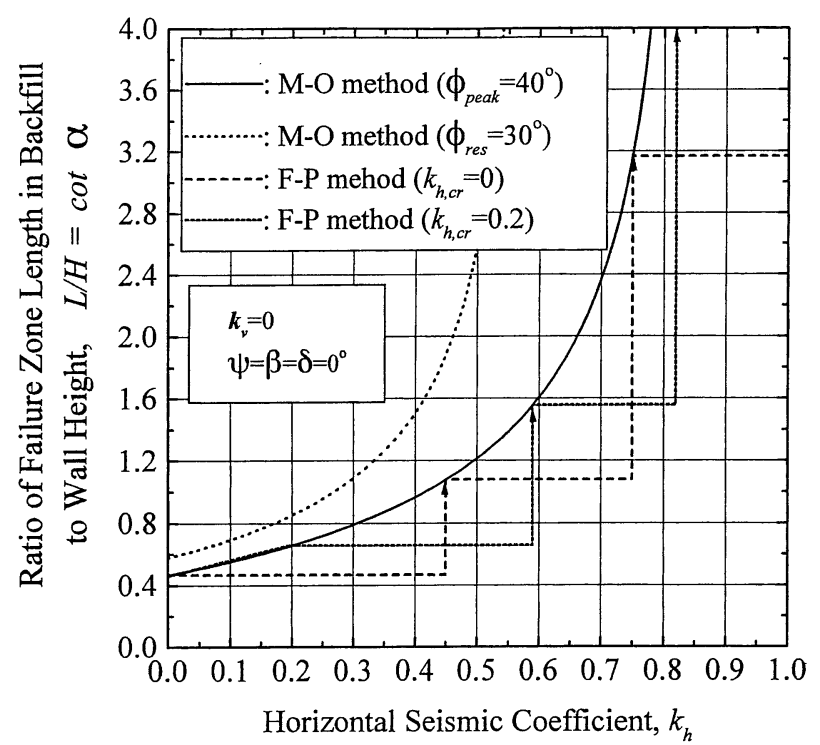

(b)

Fig. 8. (a) Active earth pressure coefficient, (b) ratio of failure zone length in backfill soil to wall height by the proposed meihod for $\phi_{\text {peak }}=40^{\circ}, \phi_{\text {res }}=30^{\circ}$ and $\delta=0^{\circ}$ 
Figs. 7(a) and (b), respectively, where $\phi_{\text {peak }}=50$ degrees, $\phi_{\text {res }}=30$ degrees, and $k_{v}, \psi, \beta$ and $\delta$ are all set at zero similarly to the aforementioned examples. The parameter $k_{h, c r}$ denotes the horizontal seismic coefficient to trigger the initial active failure, which was arbitrarily assigned either 0 or 0.2 . Corresponding values evaluated by the $\mathrm{M}$ $\mathrm{O}$ methods with $\phi=\phi_{\text {peak }}$ and $\phi=\phi_{\text {res }}$ are also shown for reference. The values of $K_{a}$ when $k_{h}=0,0.4,0.62$ and 0.8 for the case of $k_{h, c r}=0$ are equal to those indicated in Figs. 5(a) and (b) because all the assumptions are identical. It is also seen that the results for the case of $k_{h, c r}=0.2$ are different from those for $k_{h, c r}=0$ and that their difference becomes larger as $k_{h}$ increases.

Figures 8 and 9 show the effects of $\phi_{\text {peak }}$ and $\delta$ while keeping other parameters the same as in Figs. 7(a) and (b).

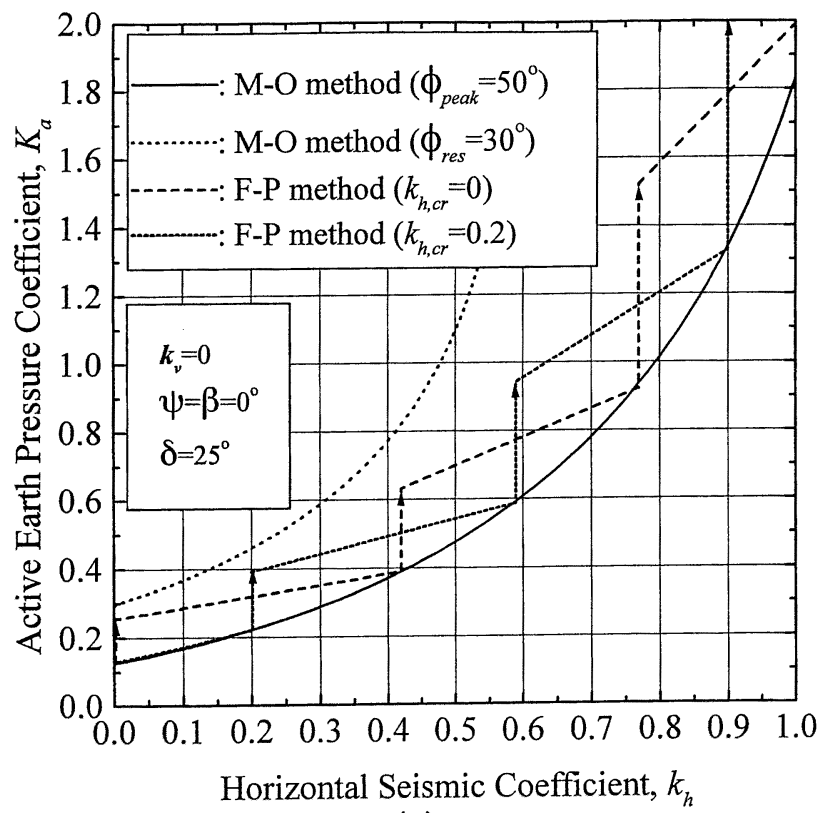

(a)

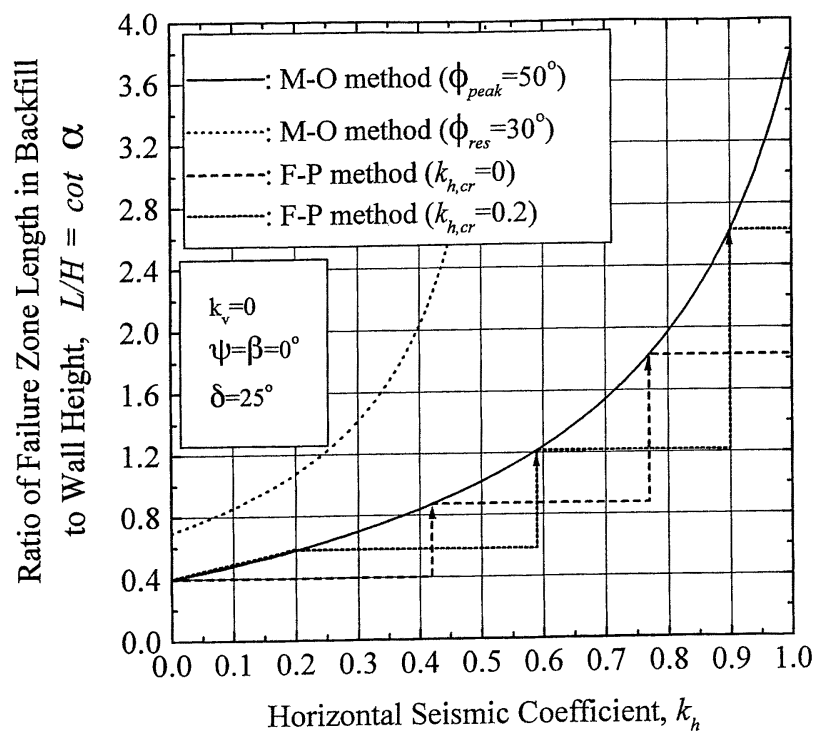

(b)

Fig. 9. (a) Active earth pressure coefficient, (b) ratio of failure zone length in backfill soil to wall height by the proposed method for

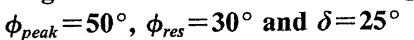

As seen in Figs. 8(a) and (b) where $\phi_{\text {peak }}$ is reduced to 40 degrees, the tertiary active failure occurs at $k_{h}=0.75$ and 0.82 , respectively, for the cases of $k_{h, c r}=0$ and 0.2 . Similar behavior is seen in Figs. 9(a) and (b), where $\delta$ is set at 25 degrees $\left(=\phi_{\text {peak }} / 2\right)$. The same procedure used to evaluate the angle of the secondary failure plane can be employed for this tertiary failure plane.

Based on the results shown in Figs. 7 to 9, the following advantages of the proposed method over the M-O method can be expected;

(1) It evaluates an active earth pressure coefficient $K_{a}$ which is larger than that predicted by the M-O method with $\phi=\phi_{\text {peak }}$; the latter method underestimates the actual pressure because the post-peak reduction of the shear resistance in the backfill soil is not considered. On the other hand, it evaluates a $K_{a}$ value which is smaller than that predicted by the M-O method with $\phi=\phi_{r e s}$; the latter value is too conservative and cannot rationally reflect differences in the $\phi_{\text {peak }}$ value for different compaction levels of the backfill.

(2) It can evaluate the active earth pressure coefficient at large $k_{h}$ values where the M-O method with $\phi=\phi_{\text {res }}$ (as employed widely in current practice) is not applicable.

(3) The failure zone length $L$ is reduced so as to be considerably smaller than that predicted by the M-O method with $\phi=\phi_{r e s}$, and even smaller than that predicted by the M-O method with $\phi=\phi_{\text {peak }}$. When effects of the failure of retaining walls on facilities that are located in or on their backfill soil are of concern, the implication of this feature is very important; based on this feature, the volume of the backfill soil which should be reinforced against such effects is largely reduced.

On the other hand, the largest disadvantage of the proposed method may be that the results are affected by estimated initial active failure conditions (i.e., the value of $k_{h, c r}$ ), although at this moment, a method to evaluate the $k_{h, c r}$ value has not been established. Further study on this point will be required. Investigations to validate the proposed procedure are in progress by means of model tests with respect to the active earth pressure coefficient $K_{a}$ and the failure plane angle $\alpha$, these will be reported in due course.

\section{CONCLUSIONS}

Based on the pseudo-static and limit-equilibrium approach, seismic active earth pressure was calculated by considering the effects of strain localization in the backfill soil and associated post-peak reduction in the shear resistance angle from $\phi_{\text {peak }}$ to $\phi_{\text {res }}$ along a previously formed failure plane. It was shown that the failure plane formed by the initial active failure in the backfill soil will control the consecutive mobilization of earth pressure at higher seismic load levels until the secondary active failure occurs along another new failure plane, which is deeper than the initial one. 
Incorporating the above-mentioned effects, a modified procedure was proposed to evaluate the active earth pressure, particulaly at high seismic load levels. The following advantages of the proposed procedure over the Mononobe-Okabe method were discussed;

(1) It can rationally reflect the differences in $\phi_{\text {peak }}$ for different backfill conditions, while it yields reasonable seismic active earth pressure, which is smaller than that predicted by the Mononobe-Okabe method with $\phi=\phi_{r e s}$; the latter value becomes unrealistically high at relatively high seismic loads.

(2) It provides a realistic and reduced size of active failure zone in the backfill soil compared to that predicted by the Mononobe-Okabe method.

\section{ACKNOWLEDGMENTS}

The present study was undertaken with the financial support of Grant-in-Aid for Scientific Research (project umber 08555119), the Ministry of Education, Science, sports and Culture. The authors wish to thank Dr. T. Yoshida of Kajima Technical Research Institute for providing the experimental data on shear band.

\section{REFERENCES}

1) Bolton, M. D. and Steedman, R. S. (1985): “Modelling the seismic resistance of retaining structures," Proc. of 11th Int. Conf. on SMFE, Vol. 4, pp. 1845-1848.

2) Ichihara, M. and Matsuzawa, H. (1973): "Earth pressure during earthquake," Soils and Foundations, Vol. 13, No. 4, pp. 75-86.

3) Ishibashi, I. and Fang, Y. S. (1987): "Dynamic earth pressures with different wall movement modes," Soils and Foundations, Vol. 27, No. 4, pp. 11-12.

4) Japan Road Association (1987): "Earthworks manual-retaining walls, culverts and temporary structures-," p. 25 (in Japanese).

5) Japan Society of Civil Engineers (1996): "Proposal on earthquake resistance for civil engineering structures (Special Task Committee of Earthquake Resistance of Civil Engineering Structures)," The 1995 Hyogoken-nanbu Earthquake-Investigation into Damage to Civil Engineering Structures-, Committee of Earthquake Engrg., Japan Society of Civil Engineers, pp. 297-306.

6) Koseki, J., Tateyama, M., Tatsuoka, F. and Horii, K. (1996): "Back analyses of soil retaining walls for railway embankments damaged by the 1995 Hyogoken-nanbu earthquake," The 1995 Hyogoken-nanbu Earthquake-Investigation into Damage to Civil Engineering Structures-, Committee of Earthquake Engrg., Japan Society of Civil Engineers, pp. 101-104.

7) Mononobe, N. and Matsuo, H. (1929): "On determination of earth pressure during earthquake," Proc. World Engrg. Congress, Tokyo, Vol. 9, pp. 177-185.

8) Ohara, S., Maehara, H. and Nagata, H. (1970): “On active earth pressure during earthquake," Tsuchi-to-Kiso, JSSMFE, Vol. 18, No. 2, pp. 27-35 (in Japanese).

9) Okabe, S. (1924): "General theory on earth pressure and seismic stability of retaining wall and dam," J. of Japan Society of Civil Engineers, Vol. 10, No. 6, pp. 1277-1323.

10) Railway Technical Research Institute (1997): "Design Standard for Railway Foundations/Soil Retaining Structures,"' p. 364 and p. 371 (in Japanese).

11) Tatsuoka, F., Tateyama, M. and Koseki, J. (1996a): “Performance of soil retaining walls for railway embankments," Soils and Foundations, Special Issue of Soils and Foundations on Geotechnical Aspects of the January 17, 1995 Hyogoken-Nambu Earthquake, pp. 311-324.

12) Tatsuoka, F., Koseki, J. and Tateyama, M. (1996b): “Performance of reinforced soil structures during the 1995 Hyogo-ken Nanbu earthquake,' Earth Reinforcement, Ochiai, Yasufuku \& Omine (eds.), A. A. Balkema, Vol. 2, pp. 973-1008.

13) Terzaghi, K. (1920): "Old earth-pressure theories and new test results," Engineering News Record, Vol. 85, No. 14, pp. 632-637.

14) Yoshida, T., Tatsuoka, F., Siddiquee, M. S. A., Kamegai, Y. and Park, C. S. (1994): "Shear banding in sands observed in plane strain compression," Localisation and Bifurcation Theory for Soils and Rocks, Chambon, Desrue and Vardoulakis (eds.), Balkema, pp. 165-179.

15) Yoshida, T. and Tatsuoka, F. (1997): "Deformation property of shear band in sand subjected to plane strain compression and its relation to particle characteristics," Proc. of 14th Int. Conf. on SMFE, Hamburg, Vol. 1, pp. 237-240. 